\title{
FORMULATION AND EVALUATION OF MEDICATED CHEWING GUM OF DOLASETRON AS AN ANTIEMETIC AGENT
}

\author{
Azra Shaikh*, Ankit Agrawal, Neetesh K Jain, Mahesh Kumar Gupta \\ Department of Pharmacy, Oriental University, Indore (M.P.), India
}

\begin{abstract}
An attempt has been made to formulate new chewing gum for Dolasetron. The new drug delivery system was obtained, at room temperature conventional pharmaceutical equipment. The resulting chewing gum comprises a gum core combined with fillers, antioxidants, coloring agent and plasticizers, which provide smooth appearance and flexibility during storage and chewing. Drug release from a dosage form is the critical step in drug absorption and bioavailability, thus an experimental work has been designed to evaluate the efficiency of this kind of therapeutic system by verifying its capability to release the drug dose and by assessing the delivery of Dolasetron for bypassing the hepatic first pass effect. Simple diffusion into the medium causes the release of only a small percentage of the drug contained in the medicated chewing gum, while the delivery of the major part of the dose occurs during mastication. In the present study, an attempt has been made to formulate the chewing gum of Dolasetron. Different formulations of chewing gum with varying concentration of plasticizers like glycerol and castor oil were formulated. MCG II formulation was considered to be the best-optimized formula which consists of synthetic gum base (45\%), Sorbitol (14.6\%), sucrose (46\%) etc. which shows first slow release the fast release in the phosphate buffer saline (ph 6.8). The cumulative drug release of MCG II formulation was found to be $99.43 \%$. From this study, we can conclude that the medicated chewing formulation can be a better choice in the coming years which provides several benefits and also benefits commercially.
\end{abstract}

Keywords: Medicated Chewing Gum, Dolasetron, Hepatic First Pass Metabolism.

Article Info: Received 11 June, 2017; Review Completed 14 July, 2017; Accepted 14 July, 2017; Available online 15 July, 2017

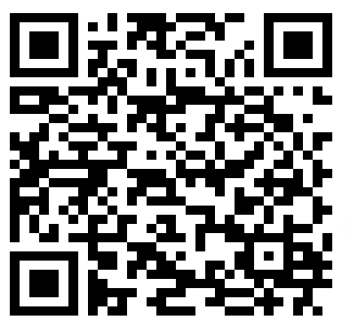

Cite this article as:

Shaikh A, Agrawal A, Jain NK, Gupta MK, Formulation and evaluation of medicated chewing gum of dolasetron as an antiemetic agent, Journal of Drug Delivery and Therapeutics. 2017; 7(4):125-128

DOI: http://dx.doi.org/10.22270/iddt.v7i4.1477

*Address for Correspondence

Azra Shaikh, PG Research Scholar, Dept. of Pharmacy, Oriental University, Indore, Email.id: azrashaikh03@gmail.com

\section{INTRODUCTION}

Drug can be administered via different routes of administration to produce a systemic pharmacologic effect. The most common method to administer drug is oral route, in which the drug is swallowed and it enters the systemic circulation. There are various dosage forms those can be administered orally. Out of which, chewing gum is most popular. It is a potentially useful means of administering drugs locally and systemically. Chewing gum has been used for centuries to clean the mouth as well as fresh the breath. The advantage of buccal route is administration has direct access to systemic circulation. This avoids first pass hepatic metabolism and local loss of the drug at site. In the present work non toxic synthetic gum base has been used in the formulation of medicated chewing gum (MCG) containing an Dolasetron as an Antiemetic Agent. ${ }^{1,2}$

Dolasetron is suitable drug to prepare MCG. Dolasetron is a selective serotonin $5-\mathrm{HT}_{3}$ receptor antagonist. In vivo, the drug is rapidly converted into its major active metabolite, hydrodolasetron, which seems to be largely responsible for the drug's pharmacological activity. The antiemetic activity of the drug is brought about through the inhibition of $5-\mathrm{HT}_{3}$ receptors present both centrally (medullary chemoreceptor zone) and peripherally (GI tract).Glycerin, Castor oil and Dibutyl phthalate were used as plasticizer in varying amount. Sucrose coating was given to the chewing gum pieces. Trial runs were performed using plasticizers in combination. When plasticizers were used in combination, it was observed that the gum formulations formed were very sticky. 3,4 


\section{MATERIALS AND METHODS}

Dolasetron was gift sample of Manus Aktteva Biopharma LLP, Ahmedabad, India and synthetic gum base from Amber Confectionaries Pvt. Ltd. Sucrose, sorbitol, magnesium stearate, talc, flavor and color were purchased from Lobachemi chemicals Pvt. Ltd, India. All other chemicals/solvents used were of analytical grade.

\section{Preparation of Medicated Chewing Gum}

All ingredients were weighed accurately as shown in formulation table 1 . Molten mass of synthetic gum base was prepared and plasticizer was mixed thoroughly in porcelain dish. The dish was kept on water bath and temperature was maintained at about $35-45^{\circ}$ C. Drug Dolasetron was then added to above mass. Corresponding amount of Sucrose and mannitol was added to above mixture with continuous stirring up to 30 min. Finally the adequate amount of flavor was incorporated in the mixture. The mass was poured in to the mould and was allowed to cool at room temperature. The gum pieces were removed. , $^{5,8}$

Coating of MCG was done by liquid coating solution of sucrose. The coating solution was sprayed uniformly. Coating was dried in hot warm air in temperature range $27^{\circ} \mathrm{C}$ to $38^{\circ} \mathrm{C}$. After cooling chewing gum pieces were wrapped properly.

\section{Physical evaluation of drug and synthetic gum base}

\section{Preliminary studies}

Physical evaluation of medicated chewing gum

The formulated chewing gum were evaluated for various physicochemical parameters including color, softening point, stickiness, weight variation, plasticity/hardness, percentage drug content and percentage cumulative invitro drug release.

\section{RESULTS AND DISCUSSION}

\section{Physical evaluation of gum base}

1. Color: Color of synthetic gum base is Pale yellow observe visually.

2. Softening point: Softening point of synthetic gum base was observed by heating the base in Petri dish. The temperature at which it starts melting is the softening point of that base. It was found to be 55$60^{\circ} \mathrm{C}$.

\section{Solubility studies of synthetic gum base}

As the gum has showed very negligible solubility in artificial saliva and phosphate buffer, it can be concluded that the procured synthetic gum base was the best for use as base for medicated chewing gum preparation.
Table 1: Solubility studies

\begin{tabular}{|c|c|c|}
\hline $\begin{array}{c}\text { Sr. } \\
\text { no. }\end{array}$ & Solvent & Solubility $(\mathbf{g m}) / \mathbf{1 0} \mathbf{~ m l}$ \\
\hline $\mathbf{1}$ & Alcohol & Up to $2 \mathrm{gm}$ \\
\hline $\mathbf{2}$ & Chloroform & Up to $17 \mathrm{gm}$ \\
\hline $\mathbf{3}$ & Acetone & Soluble \\
\hline $\mathbf{4}$ & Water & Slightly soluble \\
\hline $\mathbf{5}$ & Artificial saliva & Up to $1 \mathrm{gm}$ \\
\hline
\end{tabular}

\section{Physical evaluation of medicated chewing gum}

The formulated medicated chewing gum was evaluated physically for following parameters and is mentioned.

1. Color: The color of MCG formulation was observed visually and all the batches were light brown in color which in acceptable limit.

2. Melting point: Melting point of drug was found to be $276-279^{\circ} \mathrm{C}$ which is in standard range of $276-$ $278^{\circ} \mathrm{C}$.

3. Stickiness: The formulated medicated chewing gum was placed on plain surface. A mass of $250 \mathrm{gm}$ was hammered on it up to $10 \mathrm{~min}$. the frequency of hammering was about $30 / \mathrm{min}$. None of the batch stuck to hammer or surface.

4. Weight variation: Chewing gum from each batch was individually weighed on analytical balance, the average weight and standard deviation were calculated which was found in acceptable limit. ${ }^{3}$

5. Plasticity/hardness: Hardness of chewing gum was determined by Monsanto hardness tester and the average hardness and standard deviation were reported. ${ }^{3}$

Percentage drug content: Chewing gum was manually divided in to pieces and transferred into separating funnel containing $10 \mathrm{ml}$ of dichloromethane. Separating funnel was shaken for $10-15$ minutes so as to disperse the chewing mass. The turbid solution was shaken simultaneously with $50 \mathrm{ml}$ distill water for 15 minutes for dissolving the drug in to it. Separating funnel was kept undisturbed for 15 minutes for separation of the two phases. The aqueous phase was collected and filtered through whatman filtered papers grade 41. Filtrate was sufficiently diluted and estimated for the drug content at $285 \mathrm{~nm}$ in UV spectrophotometer. Same procedure was repeated for three times.

\section{Stability Studies of synthetic gum base}

Stability studies of synthetic gum base: $10 \mathrm{gm}$ of synthetic gum base was stored in bottle at $50^{\circ} \mathrm{C}$ for 30 days. After 30 days the gum was examined for natural ageing and physical nature. 
Table 2: Stability Studies of Synthetic Gum Base

\begin{tabular}{|c|l|l|}
\hline S. No. & Properties & Observations \\
\hline $\mathbf{1}$ & Color (before ageing) & Off white- pale yellow \\
\hline $\mathbf{2}$ & Color (after ageing) & Pale yellow \\
\hline $\mathbf{3}$ & Softening range (before ageing) & $85-90^{\circ} \mathrm{C}$ \\
\hline $\mathbf{4}$ & Softening range (after ageing) & $86-88^{\circ} \mathrm{C}$ \\
\hline
\end{tabular}

\section{UV Spectroscopy}

$\lambda$ max of Dolasetron was found to be $285 \mathrm{~nm}$ in artificial saliva solution having $\mathrm{pH} 6.4$.

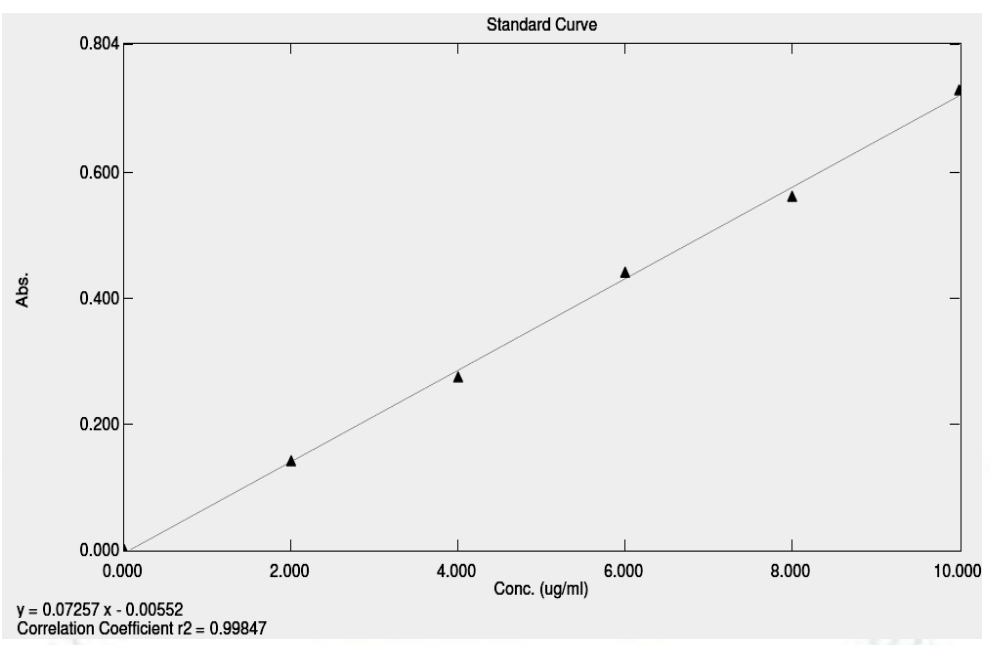

Figure 1: Calibration curve of Dolasetron.

\section{In vitro dissolution studies}

In order to study the in vitro dissolution pattern from chewing gums, it was necessary to design an apparatus, which could give same impact of mastication on MCG. This was necessary in order to mimic the human mastication. After an extensive literature survey and discussion with guide it was decided to modify the disintegration test apparatus and fabricate suitable chewing gum apparatus. Release measurements were performed using Lab fabricated medicated chewing gum test apparatus at $50 \mathrm{rpm}$. In each flask a $900 \mathrm{ml}$ of artificial saliva $\mathrm{pH} 6.4$ was filled. The temperature was maintained at $37 \pm 0.5^{\circ} \mathrm{C}$. At predetermined time intervals $(5,10,15,20,25,30$ and $35 \mathrm{~min})$ absorbance were recorded spectrophotometrically at $285 \mathrm{~nm}$ and the percentage of drug released was determined as a function of time.
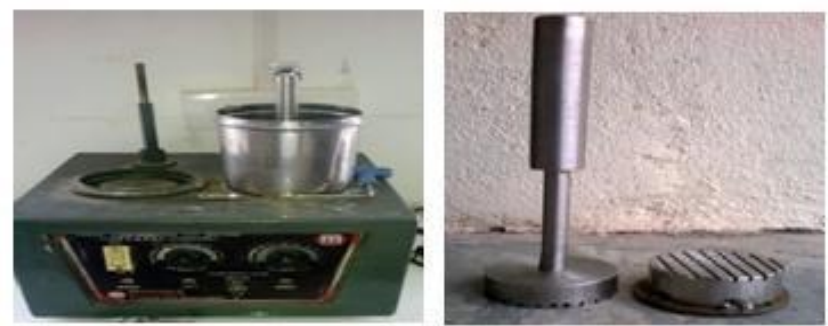

Figure 2: Lab fabricated Medicated Chewing Gum apparatus with Die and punch.

Table 3: Formulation Table.

\begin{tabular}{|l|l|l|l|l|l|}
\hline \multirow{2}{*}{ S. No } & \multirow{2}{*}{ Ingredients } & \multicolumn{3}{l}{ Percentage (\%w/w) } \\
\cline { 3 - 6 } & & MCG I & MCG II & MCG III & MCG IV \\
\hline $\mathbf{1}$ & Synthetic gum base & 25 & 35 & 45 & 55 \\
\hline $\mathbf{2}$ & Drug & $1 \%$ & $1 \%$ & $1 \%$ & $1 \%$ \\
\hline $\mathbf{3}$ & Sorbitol & 14.6 & 14.6 & 14.6 & 14.6 \\
\hline $\mathbf{4}$ & Sucrose & 56 & 46 & 36 & 26 \\
\hline $\mathbf{5}$ & Flavor & 0.6 & 0.6 & 0.6 & 0.6 \\
\hline $\mathbf{6}$ & Magnesium stearate & 0.2 & 0.2 & 0.2 & 0.2 \\
\hline $\mathbf{7}$ & Talc & 2.364 & 2.364 & 2.364 & 2.364 \\
\hline $\mathbf{8}$ & Color & Q.S & Q.S & Q.S & Q.S \\
\hline
\end{tabular}


Table 04: Cumulative \% Drug Release.

\begin{tabular}{|c|c|c|c|c|c|}
\hline \multirow{2}{*}{ S. No. } & \multirow{2}{*}{ Time(min) } & \multicolumn{4}{|c|}{ \% CUMULATIVE DRUG RELEASE \pm SD } \\
\cline { 3 - 6 } & & MCG I & MCG II & MCG III & MCG IV \\
\hline $\mathbf{1}$ & 0 & 0 & 0 & 0 & 0 \\
\hline $\mathbf{2}$ & 2 & $30.2 \pm 0.90$ & $23.4 \pm 0.29$ & $28.8 \pm 0.16$ & $32.4 \pm 0.40$ \\
\hline $\mathbf{3}$ & 4 & $50.41 \pm 0.53$ & $36.78 \pm 0.32$ & $42.12 \pm 0.35$ & $42.54 \pm 0.24$ \\
\hline $\mathbf{4}$ & 6 & $57.51 \pm 0.20$ & $45.36 \pm 0.35$ & $50.62 \pm 0.20$ & $48.12 \pm 0.32$ \\
\hline $\mathbf{5}$ & 8 & $66.07 \pm 0.17$ & $53.67 \pm 0.32$ & $57.43 \pm 0.33$ & $59.03 \pm 0.17$ \\
\hline $\mathbf{6}$ & 10 & $69.56 \pm 0.28$ & $62.34 \pm 0.57$ & $65.36 \pm 0.47$ & $66.23 \pm 0.03$ \\
\hline $\mathbf{7}$ & 12 & $73.74 \pm 0.27$ & $74.62 \pm 0.42$ & $69.32 \pm 0.17$ & $70.50 \pm 0.26$ \\
\hline $\mathbf{8}$ & 15 & $78.98 \pm 0.53$ & $86.34 \pm 0.35$ & $72.33 \pm 0.33$ & $74.06 \pm 0.41$ \\
\hline $\mathbf{9}$ & 20 & $83.28 \pm 0.20$ & $90.08 \pm 0.15$ & $79.66 \pm 0.27$ & $82.43 \pm 0.06$ \\
\hline $\mathbf{1 0}$ & 25 & $89.12 \pm 0.16$ & $96.34 \pm 0.24$ & $88.64 \pm 0.34$ & $85.21 \pm 0.36$ \\
\hline $\mathbf{1 1}$ & 30 & $94.56 \pm 0.31$ & $99.43 \pm 0.32$ & $96.45 \pm 0.36$ & $92.45 \pm 0.12$ \\
\hline
\end{tabular}

\section{CONCLUSION}

Medicated chewing gum (MCG) is solid, single dose preparations with a base consisting mainly of gums that are intended to be chewed but not swallowed. Medicated chewing gum (MCG) is a novel drug delivery system containing masticatory gum base with pharmacologically active ingredient and intended to use for local treatment of mouth diseases or systemic absorption through oral mucosa.

Furthermore, in case of buccal absorption, it is likely that the dose could be decreased due to the avoidance of first pass metabolism, and thus, fewer side effects will be seen. As the fear of side effects is predominant among patients, a Medicated Chewing gum formulation with lesser amount of active ingredient is likely to be favored by the patients.

Antiemetic drug Metoclopramide, Domperidone, Cisapride (prokinetic drug), Neuroleptic drug, Chlorpromazine, Prochlorperazine, Haloperidol, 5-HT3 antagonists Ondansetron are less suitable for treatment of motion sickness, they are more suitable for emesis induced by cytotoxic drug or emesis caused due to post operative vomiting. Diphenhydramine Hydrochloride based on its higher salivary solubility and fewer side effects (no extra pyramidal effect) is the suitable candidate for formulation of MCG for prevention of motion sickness.

MCG II formulation was considered to be best optimized formula which consists of synthetic gum base (45\%), sorbitol (14.6\%), sucrose (46\%) etc. which shows first slow release the fast release in the phosphate buffer saline $(\mathrm{pH}$ 6.8). The cumulative drug release of MCG II formulation was found to be $99.43 \%$. From this study we can conclude that the medicated chewing formulation can be better choice in the coming years which provides several benefits and also benefits commercially.

\section{REFERENCES}

1. Paradkar M, Gajra B, Patel B, Formulation development and evaluation of medicated chewing gum of anti-emetic drug, Saudi Pharmaceutical Journal, 2016; 24:153-164.

2. Shah KR, Mehta TA, Medicated Chewing Gum- A Mobile Oral Drug Delivery System, International Journal of PharmTech Research, 2014; 6(1):35-48

3. Pathan JA, Nitalikar MM, Formulation and Evaluation of Medicated Chewing Gum Containing Antibacterial Agent. Journal of Current Pharma Research 2014; 4(4):1291-1296
4. John F. Golding. Motion Sickness Susceptibility, Autonomic Neuroscience: Basic and Clinical. 2006; 129:67-76.

5. Neil A. Minton. Volunteer Models for Predicting Antiemetic Activity of 5-HT3 Receptor Antagonists, British Journal of Clinical Pharmacology, 1994; 37:525-530.

6. Ezhumlai K, Rajalakshmi A.N., Ilavarasan P, Sathiyaraj U., Murali Mugundhan R. Medicated Chewing Gum- A Novel Drug Delivery Technique For Systemic and Targeted Drug Delivery, International Journal of Pharmacy \& Technology, 2011; 3:725-744.

7. Patel VP. Medicated Chewing Gum: A Review, International Journal of Universal Pharmacy and Life Sciences, 2011; 1:111-128.

8. Savaliya P, Karikar A, Ramana MV. Chewing Gum: A Modern Era of Drug Delivery, international research journal of pharmacy, 2011; 2(10):7-12.

9. Kumar D, Rathi L, Tripathi A, Maddheshiya YP. A Review on Oral Mucosal Drug Delivery System, International Journal of Pharmaceutical Science and Research. 2010; 1:50-56.

10. Surana AS. Chewing Gum: A Friendly Oral Mucosal Drug Delivery System, International Journal of Pharmaceutical Science Review and Research. 2010; 4:68-71.

11. Jain H, Shah M, Shah B, Pasha TY, Medicated Chewing Gum: A Novel Oral Drug Delivery, International Journal of Drug Formulation \& Research, 2010; 1:80-96.

12. Venkat Mateti U, Adla N, Rajakannan T, Valakkathala R. Insulin Chewing Gum: Need of the day for Diabetic patients, International Journal of Pharmaceutical Investigation. 2011; 1:131-134.

13. Naik H, Gupta S.Medicated Chewing Gum- Updated Review, International Journal of Pharma Research \& Development, 2010; 2:66-76.

14. Pandey S, Goyani M, Devmurari V. Development, In-Vitro Evaluation and Physical Characterization of Medicated Chewing Gum: Chlorohexidine Gluconate, Scholars Research Library, 2009; 2:286-292.

15. Jayachandar Gajendran, Johannes Kraemer, Stig Randers Knudsen. Product Performance Test for Medicated Chewing Gums, Pharmacopeial Forum, 2008; 34:843-847.

16. Catharina Kvist L, Sven-Bo Rje Andersson, Johan Berglund, Bo Wennergren, Susan M. Fors. Equipment for Drug Release Testing of Medicated Chewing Gums, Journal of Pharmaceutical and Biomedical Analysis, 2000; 22:405-411.

17. Gavaskar B, Venkata Ramana D, Y Madhusudan Rao. Medicated Chewing Gum - A Novel Approach to Improve Patient Compliance, International Journal of Research in Pharmaceutical and Biomedical Sciences, 2011; 2; 23-32.

18. Madan N, Rathnam A. Chewing Gum for Optimal Health, Chronicles of Young Scientist, 2011; 2:7-10.

19. Patel Y, Shukla A, Saini V, Shrimal N, Sharma P. Chewing Gum as a Drug Delivery System, International Journal of Pharmaceutical Sciences and Research, 2010; 2:748-757.

20. Andrew PLR. Bhandari P. The 5- Hydroxytrytryptamin Receptor Antagonist as Antiementis: Practical Evolution and Mechanism at Action, European Journal of cancer. 1990; 29:511-516. 